\title{
Article \\ Microscopic Object Classification through Passive Motion Observations with Holographic Microscopy
}

\author{
Devan Rouzie $^{1}$, Christian Lindensmith ${ }^{2}$ and Jay Nadeau ${ }^{1, *}$ \\ 1 Department of Physics, Portland State University, 1719 SW 10th Ave., Portland, OR 97201, USA; \\ rouzie@pdx.edu \\ 2 Jet Propulsion Laboratory, California Institute of Technology, Pasadena, CA 91125, USA; \\ christian.a.lindensmith@jpl.nasa.gov \\ * Correspondence: nadeau@pdx.edu; Tel.: +1-503-795-8929
}

Citation: Rouzie, D.; Lindensmith,

C.; Nadeau, J. Microscopic Object Classification through Passive Motion Observations with Holographic

Microscopy. Life 2021, 11, 793.

https://doi.org/10.3390/life11080793

Academic Editor: Amedeo Balbi

Received: 1 July 2021

Accepted: 1 August 2021

Published: 5 August 2021

Publisher's Note: MDPI stays neutral with regard to jurisdictional claims in published maps and institutional affiliations.

Copyright: (c) 2021 by the authors. Licensee MDPI, Basel, Switzerland. This article is an open access article distributed under the terms and conditions of the Creative Commons Attribution (CC BY) license (https:// creativecommons.org/licenses/by/ $4.0 /)$.

\begin{abstract}
Digital holographic microscopy provides the ability to observe throughout a volume that is large compared to its resolution without the need to actively refocus to capture the entire volume. This enables simultaneous observations of large numbers of small objects within such a volume. We have constructed a microscope that can observe a volume of $0.4 \mu \mathrm{m} \times 0.4 \mu \mathrm{m} \times 1.0 \mu \mathrm{m}$ with submicrometer resolution (in xy) and $2 \mu \mathrm{m}$ resolution (in $\mathrm{z}$ ) for observation of microorganisms and minerals in liquid environments on Earth and on potential planetary missions. Because environmental samples are likely to contain mixtures of inorganics and microorganisms of comparable sizes near the resolution limit of the instrument, discrimination between living and non-living objects may be difficult. The active motion of motile organisms can be used to readily distinguish them from non-motile objects (live or inorganic), but additional methods are required to distinguish non-motile organisms and inorganic objects that are of comparable size but different composition and structure. We demonstrate the use of passive motion to make this discrimination by evaluating diffusion and buoyancy characteristics of cells, styrene beads, alumina particles, and gas-filled vesicles of micron scale in the field of view.
\end{abstract}

Keywords: holographic microscopy; Brownian motion; Strouhal; buoyancy; life detection; astrobiology; Europa; Enceladus

\section{Introduction}

There is growing interest in the search for potential extant microbial life elsewhere within the Solar System, especially on the so-called Ocean Worlds such as Europa [1-3] and Enceladus [4-6]. The best methods for detecting purely microbial life are still a matter of debate, but some type of microscopy is essential for discrimination between chemistry and extant life, and a microscope (type unspecified) has been recommended for any Europa lander [7]. A perpetual issue in using microscopy for detection of new extant life is the misidentification of objects: either false positives in which non-living objects are identified as alive, or false negatives in which living objects are mistaken for abiotic particles. With optical imaging, this is particularly difficult in the 0.2 to $2 \mu \mathrm{m}$ range, where the dimensions are in the order of a wavelength and barely resolved. Objects smaller than $0.2 \mu \mathrm{m}$ are unlikely to be alive, or at least incapable of life in the absence of larger organisms to parasitize [8]. Larger objects are less of a problem, as they can be analyzed for sub-cellular structure and possibly even behavior.

Approaches to discriminating objects in this size range include fluorescence imaging [9] and active motility [10]. Fluorescence imaging is widely used for bacterial enumeration [11], and may be used to detect the presence of organic molecules of various types (e.g., lipids, proteins, nucleic acids) that would indicate probable biotic origin. Motility, or motion that is inconsistent with simply traveling with the background fluid or sinking/floating, is a strong indicator of likely extant life. It can also serve as a proxy for metabolism, since 
energy must be acquired and spent by an organism to move independently of the fluid around it. Motility can also be a response to stimuli, such as nutrients, energy sources, or toxins. Detailed characterization of microbial motility in oligotrophic environments has only begun to be performed [12,13].

Passive motion resulting from molecular collisions and gravitational effects is also important at the microbial scale; motility in some environments is energetically unfavorable since nutrients are more readily encountered via diffusion [14]. As a result, many important species are nonmotile, such as the ubiquitous marine organism Prochlorococcus. In this paper we develop an approach using passive vertical motion of particles in a background fluid to determine whether they are more likely to be cell-like or of mineral origin. This analysis is based upon density and the resulting time scales of Brownian motion versus sinking or floating.

Single-celled organisms that live in aqueous environments tend to have internal cellular fluids that are very similar in composition to their external medium, resulting in a density that is close to that of the external medium (on Earth this is typically water). Though limited data are available, the composition of bacterial cells is approximately $2 / 3$ water and $1 / 3$ other materials, where the other materials collectively have a specific gravity of about 1.3 [15]. This gives a specific gravity for a typical bacterial cell of about 1.1. Diatoms, which build a silica cell wall structure, or frustule, have a higher specific gravity of about $1.2[16,17]$. Cells of either type may regulate their buoyancy by using ion pumps on the cell membrane to change their volume or contents. Some diatoms have external structures that slow their sinking rate. Cyanobacteria are unique in being able to regulate their buoyancy by means of intracellular air-filled vesicles, resulting in cells with positive buoyancy [18]. These vesicles may be purified from the cyanobacteria and used for labeling other cells as they provide contrast for quantitative phase and ultrasonic imaging and MRI $[19,20]$. Their density, which is that of air surrounded by a thin protein shell, has an average reported value of $0.119 \mathrm{mg} / \mu \mathrm{L}$ [21].

Minerals, in contrast, almost universally have densities much higher than that of water. Very few have specific gravity of less than 1.6, leaving a gap between the density of microorganisms and minerals. Among simple metal oxides, the least dense are lithium oxide $\left(\mathrm{Li}_{2} \mathrm{O}\right)$ and silica $\left(\mathrm{SiO}_{2}\right)$, with specific gravities of 2 and 2.08, respectively. Some amorphous forms of silica can have effective densities as low as $\sim 1.6 \mathrm{~g} / \mathrm{cm}^{3}$ as a result of their processing. Some salts have lower densities: sodium borate decahydrate $\left(\mathrm{Na}_{2} \mathrm{~B}_{4} \mathrm{O}_{7} \cdot 10 \mathrm{H}_{2} \mathrm{O}\right)$, magnesium carbonate $\left(\mathrm{MgCO}_{3}\right)$, and carnalite $\left(\mathrm{KClMgCl}_{2}\left(\mathrm{H}_{2} \mathrm{O}\right)_{6}\right)$ have specific gravities of $1.7,1.73$, and 1.57 respectively.

Table 1 shows densities for a number of materials of interest for planetary life detection missions, including a line for generic "ocean biominerals," as described in [22]. The gap between the least dense minerals and the densest bacteria suggests that even a coarse $( \pm \sim 10 \%)$ ability to measure particle density can provide valuable insight into whether a passively moving microscopic object is more likely to be a cell or cell-like vesicle or an abiotic mineral. Similar considerations have been used for identification of nanopropulsion in particle solutions [23].

We have previously constructed multiple digital holographic microscopes (DHM) designed for observation of bacteria in aqueous environments [24-26]. The instruments are designed with a large observed volume so that large numbers of micrometer-scale objects can be observed simultaneously over time, with up to 15 frame-per-second image acquisition. The nature of the DHM allows us to record the 3D positions of all particles in the field of view at once, without active focus, and then reconstruct time series consisting of image stacks at each time point after the fact. The image stacks can be analyzed for particle positions, and those positions tracked over time to obtain particle trajectories. 
Table 1. Density of various materials is the difference between the material and water at $20{ }^{\circ} \mathrm{C}$.

\begin{tabular}{|c|c|c|}
\hline Material & Density $\left(\mathrm{kg} / \mathrm{m}^{3}\right)$ & $\left(\mathrm{kg} / \mathrm{m}^{3}\right)$ \\
\hline Water & 998 at $20^{\circ} \mathrm{C}$ & 0 \\
\hline Bacterial Cell & 1100 & 102 \\
\hline Diatom Cell & $1100-1200$ & $102-202$ \\
\hline Carnalite & 1570 & 572 \\
\hline Suspended Ocean Minerals & 1600 & 602 \\
\hline Borax (Decahydrate) & 1700 & 702 \\
\hline Silica & 2080 & 1082 \\
\hline Calcium Carbonate & 2710 & 1712 \\
\hline Alumina & 2930 & 1932 \\
\hline Polystyrene & 1050 & 52 \\
\hline Anabaena Gas Vesicles & 119 & -879 \\
\hline
\end{tabular}

The utility of DHM for detection of microorganisms (especially in sparse environmental samples) has been demonstrated for numerous applications, such as diagnostics, water quality measurements, and ocean monitoring of microbial populations and behavior [27-34]. The technique has also been used to investigate the basic biophysics of microbial motility [35-39]. Our research has focused on its applications to astrobiology, using bacterial motility, phase contrast, and in some cases morphology, to discriminate between living and non-living particles $[10,25,40,41]$. However, classification of non-motile particles at the instrument's resolution limit remains difficult. The goal of the current study is to aid in disambiguation by observing size- and density-related passive motion of micrometer-sized particles. The particular ability of DHM to observe and record the passive motion of small particles in three dimensions allows us to compare the effects of Brownian motion and gravity to classify particles as potentially cells or minerals based on their density. Unlike typical microscope slide preparations, DHM interrogates a large volume relative to bacterial cells.

In a quiescent liquid volume, motion perpendicular to gravity is driven by Brownian motion, and gives information about particle size and surface properties through the diffusivity. Uniform drift of objects can also be subtracted off, leaving just the Brownian motion. Motion parallel to gravity is driven by a combination of gravity and Brownian motion, where the relative influence of each is determined by the size, surface properties, and density of the particle.

Here we develop a model for particle buoyancy based upon Strouhal number, which is the ratio of the time scales involved in Brownian vs. gravitational motion first described in 1878 [42,43]. We then compare the theoretical model with experimental results obtained using four different micrometer-scale test systems of different buoyancy: alumina beads with negative buoyancy, air-filled cyanobacterial protein vesicles with positive buoyancy, styrene beads with neutral buoyancy, and non-motile bacteria with close to neutral buoyancy. We find that tracking of DHM trajectories shows distinct differences among the different types of particle, with excellent agreement between predicted and observed Strouhal numbers.

\section{Materials and Methods}

\subsection{Holographic Microscopy}

Holographic microscopy was performed using a custom off-axis common path instrument as described previously [24]. Briefly, the paired objective lenses had a numerical aperture (NA) of 0.3 , yielding an effective magnification of $19.6 \times$. The wavelength used was $405 \mathrm{~nm}$, supplied by a diode laser (Thorlabs S1FC405); at this wavelength, the microscope's lateral spatial resolution as measured with an air force test target was $0.8 \mu \mathrm{m}$. Samples for recording were diluted into a $1.0 \mathrm{~mm}$ deep chamber having both a reference channel (filled with medium or $\mathrm{H}_{2} \mathrm{O}$ ) and a sample channel. The chamber was bounded by a microscope slide and coverslip. 
Data acquisition was performed using a custom open-source software package, DHMx [44]. All recordings were performed at a frame rate of $15 \mathrm{fps}$ for a total of 20-60 s per recording. Reconstruction in amplitude and/or phase was performed using the angular spectrum method [45] using custom Fiji plug-ins as previously described [46]. Phase reconstructions made use of a reference hologram to remove noise [47]; this reference hologram was the median of all holograms in the recording. The lateral field of view was $356 \mu \mathrm{m} \times 365 \mu \mathrm{m}$ for $2048 \times 2048$ pixels, and the axial z-spacing was chosen to be $1-2 \mu \mathrm{m}$ based upon the particle size and nominal axial resolution of the system of $2 \mu \mathrm{m}$.

\subsection{Samples}

Aluminum oxide beads were obtained from Micro Abrasives Corp (Westfield, MA, USA, product BG1200). The beads were diluted into phosphate-buffered saline (PBS) to yield 50-100 beads per field of view in any one $2048 \times 2048$ pixel frame.

Blue-dyed polystyrene microspheres of nominal diameter $1.0 \mu \mathrm{m}$ were purchased from Polysciences Inc. (Warrington, PA, USA) (Catalog Number 15712) and diluted to a concentration of $10^{-4} \mathrm{M}$ in $\mathrm{H}_{2} \mathrm{O}$.

Protein-coated air-filled vesicles were purified from the buoyant alga Anabaena flosaquae as previously described $[19,20]$. The $100 \mathrm{~nm}$-scale vesicles were clustered by first biotinylating with $10^{5}$ molar excess of EZ-Link-Sulfo-NHS-LC-biotin (ThermoFisher Scientific, Waltham, MA, USA) in PBS for $4 \mathrm{~h}$. After dialyzing twice vs. PBS, the biotinylated vesicles were clustered by incubation with streptavidin (Geno Technology, St. Louis, MO, USA) for $30 \mathrm{~min}$ at room temperature at a streptavidin-to-vesicle ratio of 100:1. The resulting clusters were diluted into PBS for recording.

Non-motile bacteria used in this study were Staphylococcus epidermidis (ATCC 14990) grown overnight in Lysogeny broth (LB, ThermoFisher Scientific, Waltham, MA, USA) at $37^{\circ} \mathrm{C}$ in a shaking incubator to mid-log phase. On the day of the experiment, the culture was diluted into minimal medium $(10 \mathrm{mM}$ potassium phosphate, $10 \mathrm{mM} \mathrm{NaCl}, 0.1 \mathrm{mM}$ EDTA, $0.1 \mathrm{mM}$ glucose, $\mathrm{pH} 7.0$ ) to $10^{6}-10^{7}$ cells $/ \mathrm{mL}$ for recording.

\subsection{Data Processing and Analysis}

All manipulations were performed in Fiji [48]. Reconstruction in amplitude or phase produced varying degrees of contrast using the different materials, the selection of which to use was made empirically for each sample.

For the aluminum oxide beads and gas vesicles, holograms were reconstructed in phase, and z-localization was performed using a z-derivative approach as described previously [49].

For the bacteria and polystyrene beads, raw holograms were median-subtracted to increase fringe contrast as previously reported [50]. The holograms were then reconstructed in amplitude.

$X Y$ tracking and calculation of the diffusion coefficients were performed using maximum intensity protections of the z-stack at each time point, to create an XYT stack. The plug-in NanoTrackJ [51] was used to determine diffusivity. $X Z$ tracking was performed by reslicing the XYZT hyperstack to create an XZYT hyperstack, then maximum projecting in $Y$ to create an XZT hyperstack. $Z$ velocities were obtained using NanoTrackJ (for bacteria and polystyrene) or TrackMate (for alumina and gas vesicles).

\subsection{Particle Sizing}

The hydrodynamic diameter of the polystyrene microspheres was measured using a DynaPro Plate Reader III (Wyatt Technology, Santa Barbara, CA, USA). Samples were thoroughly mixed prior to analysis. Measurements were made 13 times for the reported hydrodynamic diameter.

The hydrodynamic diameter of the aluminum oxide beads and gas vesicle clusters was measured using a Zeta-PALS (Brookhaven Instruments, Holtsville, NY, USA). Samples were thoroughly mixed prior to analysis. Measurements were made five times for the reported hydrodynamic diameters. 


\section{Results}

\subsection{Model and Predicted Strouhal Numbers}

The time scale of Brownian motion is defined by the Einstein-Stokes diffusion coefficient $D$, measured in $\mathrm{m}^{2} / \mathrm{s}$ and given by

$$
D=\frac{k_{B} T}{6 \pi \eta r}
$$

where $k_{B}$ is Boltzmann's constant, $T$ is the absolute temperature, $\eta$ is the dynamic viscosity of the medium (1.002 $\mathrm{mPa} \cdot \mathrm{s}$ at $20^{\circ} \mathrm{C}$ for water), and $r$ is the radius of the particle. At $20^{\circ} \mathrm{C}$, this works out to $D=\frac{0.2146}{r} \frac{\mu \mathrm{m}^{2}}{\mathrm{~s}}$. In one dimension, a particle will cover an RMS distance $<x^{2}>_{R M S}$ on a time scale

$$
\tau_{B}=\frac{\left\langle x^{2}\right\rangle_{R M S}}{2 D}
$$

or in two dimensions, a distance $<x^{2}+y^{2}>_{R M S}$

$$
\tau_{B}=\frac{\left\langle x^{2}+y^{2}\right\rangle_{R M S}}{4 D}
$$

For gravity, settling or rising is described by Stokes' Law, which gives a settling velocity $v$ that depends upon the difference between the particle density $\rho_{p}$ and fluid density $\rho_{f}$ :

$$
v=\frac{2\left(\rho_{p}-\rho_{f}\right) g r^{2}}{9 \eta} .
$$

The timescale needed to traverse a distance $d$ is

$$
\tau_{g}=\frac{9 \eta d}{2\left(\rho_{p}-\rho_{f}\right) g r^{2}} .
$$

If the RMS distance and z-distance are both set equal to the particle radius $r$, this gives the Strouhal number $S r_{p}$ as

$$
S r_{p}=\frac{\tau_{g}}{\tau_{B}}=\frac{3 k_{B} T}{4 \pi\left(\rho_{p}-\rho_{f}\right) g r^{4}} .
$$

When experimentally determining $S r_{p}$, the diffusivity in $x$ and /or $y$ may be used to estimate the radius of each particle. Sinking or floating rates in $\mathrm{z}$ independent of diffusivity may be used with Equation (4) to get $\rho_{p}-\rho_{f}$. Because of the high sensitivity of $S r_{p}$ to radius, it is important that the measurements be made on each particle independently, since a spread of particle sizes will lead to a significant variation in $S r_{p}$ values even within a fairly homogeneous distribution. Gravity and Brownian motion are of equal importance when $S r_{p} \sim 1$. Brownian motion can be ignored for $S r_{p}<<1$; such objects will sink or float rapidly. Note that knowledge of the fluid viscosity is required. For laboratory experiments this can be easily measured or found in tables for known fluids, but for planetary missions a calibration sample with beads of known size and density can be added to the native fluid to obtain viscosity measurements.

The particles used in this study were found by dynamic light scattering (DLS) to have mean diameters $\pm 95 \%$ C.I. of: polystyrene microspheres, $1944 \pm 762 \mathrm{~nm}$; gas vesicle clusters, $690 \pm 56 \mathrm{~nm}$; aluminum oxide beads, $1524 \pm 470 \mathrm{~nm}$. S. epidermidis is spherical and $0.5-1.5 \mu \mathrm{m}$ in diameter. Assuming density values as in Table 1 gives the predicted $S r_{p}$ for the four types of particle across a range of radii as shown in Figure 1A. It can be appreciated from the graph that bacteria and polystyrene beads in the range of our samples will have Strouhal numbers close to 1, indicating that they should be dominated 
by Brownian motion. Gas vesicle clusters and alumina beads, on the other hand, should show significant sinking (alumina) or floating (vesicles), with the largest particles showing the greatest effect.
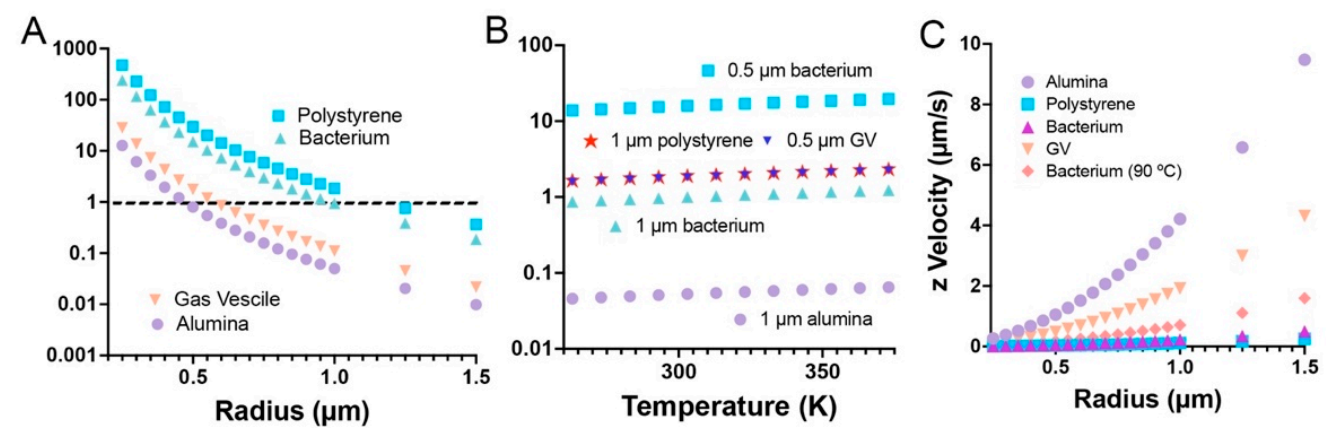

Figure 1. Behavior of typical particles. (A) Strouhal number as a function of radius at $20^{\circ} \mathrm{C}$. (B) Strouhal number as a function of temperature for selected radii. (C) Settling velocity of particles at $20^{\circ} \mathrm{C}$; bacteria at $90{ }^{\circ} \mathrm{C}$ added for comparison.

Because the Strouhal number and temperature are linearly proportional, the relative differences between the values hold true across all temperatures. This is illustrated in Figure $1 \mathrm{~B}$ where Strouhal numbers are plotted as a function of temperature for our particles between -10 and $100^{\circ} \mathrm{C}$.

It is important to note that axial resolution is the limiting factor in most volumetric microscopy techniques, so particles must rise or sink enough for the motion to be resolved during the time course of the recording in order to obtain a good value of the Strouhal number. For particles with densities much different from that of water, this does not pose a problem, as expected settling velocities are several micrometers per second in Earth's gravity. However, for cells and polystyrene, resolving z motion may be difficult. Increasing the temperature to reduce the viscosity of water will increase setting velocities appreciably, as the dynamic viscosity of water is reduced more than 3 -fold between $20{ }^{\circ} \mathrm{C}$ and $90{ }^{\circ} \mathrm{C}$ (from 1.0016 to $0.31417 \mathrm{mPa} \cdot \mathrm{s}$ ) (Figure 1C). Conversely, when particles move rapidly, it is important to begin recording immediately after placing the particles into the sample chamber, or they will float or sink to the boundaries of the chamber within seconds.

\subsection{Experimental Determination of Size and Diffusivity}

The timescales of Brownian motion may be determined by $2 \mathrm{D}$ tracking of $\mathrm{XY}$ motion. Figure 2A shows a frame from a tracked dataset of alumina beads, gas vesicles, and S. epidermidis with an overlay of identified tracks, with resulting diffusivity and diameter measurements. Videos of particle motion are given in Supplementary Video S1 (alumina), S2 (S. epidermidis), and S3 (gas vesicles). Data are shown in Figure 2B,C. Because the distributions of sizes and diffusivities were not Gaussian, histograms are given rather than means, with the median value more representative of the population than the mean. The results agree very well with the predicted Einstein values. Figure $2 \mathrm{~B}$ shows estimated diameters using the Walker method [52]. The estimated diameter of the alumina beads had two prominent peaks between 1 and $2 \mu \mathrm{m}$, consistent with the DLS result. The measured diameters of $S$. epidermidis and the polystyrene beads were unimodal and strongly peaked at $1.0 \mu \mathrm{m}$, indicating that these particles did not exhibit significant clustering. The estimated size of the polystyrene beads matched the manufacturer's specification sheet but was smaller than what we observed using DLS. The gas vesicles showed multiple peaks at increments of $0.8 \mu \mathrm{m}$, indicating that significant clusters formed in this sample. The diameter as measured by diffusivity was in excellent agreement with the results found by DLS. Figure $2 \mathrm{C}$ shows histograms of diffusion coefficients for the different samples. Statistics of the distributions ( $\mathrm{N}>100$ for all measurements) with outliers $>1.20 \mu \mathrm{m}^{2} / \mathrm{s}$ excluded were: S. epidermidis: mean $\pm 95 \%$ confidence interval, $0.45 \pm 0.02 \mu \mathrm{m}^{2} / \mathrm{s}$; median, 0.41 ; expected Einstein value, 0.43 based upon $r=0.5 \mu \mathrm{m}$; polystyrene, mean $\pm 95 \%$ confidence interval, 
$0.44 \pm 0.02 \mu \mathrm{m}^{2} / \mathrm{s}$; median, 0.40 ; expected Einstein value, 0.43 based upon $\mathrm{r}=0.5 \mu \mathrm{m}$; alumina, mean $\pm 95 \%$ confidence interval, $0.37 \mu \mathrm{m}^{2} / \mathrm{s}$; median, 29 ; expected Einstein value, 28 based upon $\mathrm{r}=0.75 \mu \mathrm{m}$. For the gas vesicles, only values above $180 \times 10^{-5} \mathrm{~cm}^{2} / \mathrm{s}$ were excluded, giving a mean $\pm 95 \%$ confidence interval, $44 \pm 2 \times 10^{-5} \mathrm{~cm}^{2} / \mathrm{s}$; median, 31 . This reflects the clustering of the vesicles that gives the dominant size as $>1 \mu \mathrm{m}$ in diameter.
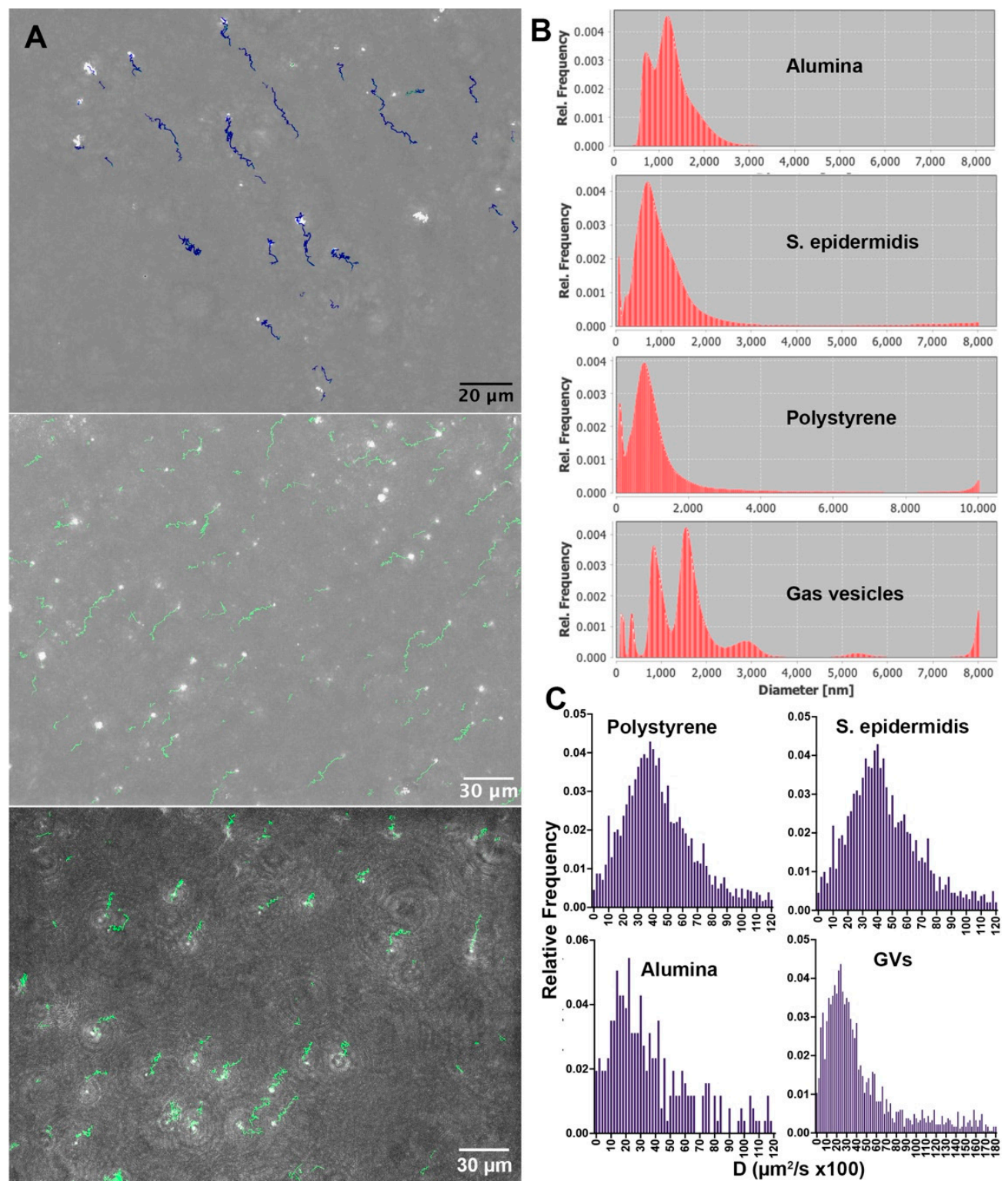

Figure 2. Results from $X Y$ tracking. (A) Holographic reconstructions: top, maximum intensity phase projection of alumina beads through $\mathrm{z}$, with corresponding tracks over $77 \mathrm{~s}$; middle, maximum intensity phase project of gas vesicles with tracks over $54 \mathrm{~s}$ (note the size heterogeneity); bottom; maximum intensity amplitude projection of S. epidermidis with tracks over $30 \mathrm{~s}$. There is some degree of $\mathrm{XY}$ drift in all images, which is accounted for. (B) Size histograms as estimated by the Walker method. (C) Diffusion coefficients.

\subsection{Particle Axial Motion}

Tracks without significant $\mathrm{z}$ motion indicate that Brownian motion dominates, as in the case of S. epidermidis (Figure 3A) or the polystyrene beads (not shown) (see Supplementary Video S4 for a video of S. epidermidis XZ motion, and Video S5 for polystyrene). In these cases, NanoTrackJ was used to estimate diffusivity. Any $z$ motion would be apparent as drift averaged over all of the particles, rather than on a particle-by-particle basis. The 
result of this tracking was an overall $z$ motion of $S$. epidermidis of $0.2 \mu \mathrm{m} / \mathrm{s}$. The same procedure was performed for the polystyrene beads, and the measured value over the same time frame was $0.03 \mu \mathrm{m} / \mathrm{s}$ (also see Supplementary Video S5). Figure 3B shows densities $\rho_{p}-\rho_{f}$ calculated from $z$ velocities according to Equation (3) for these two types of particles. The mean $\pm 95 \%$ CI value for S. epidermidis was $100 \pm 8 \mathrm{~kg} / \mathrm{m}^{3}$, median 93 , in excellent agreement with the estimates in Table 1 . For polystyrene, most of the measured densities differed from water by less than $20 \mathrm{~kg} / \mathrm{m}^{3}$, making these beads distinctly different from the bacterial cells. Figure 3C shows Strouhal number distributions for S. epidermidis and polystyrene, again illustrating the clear differences.
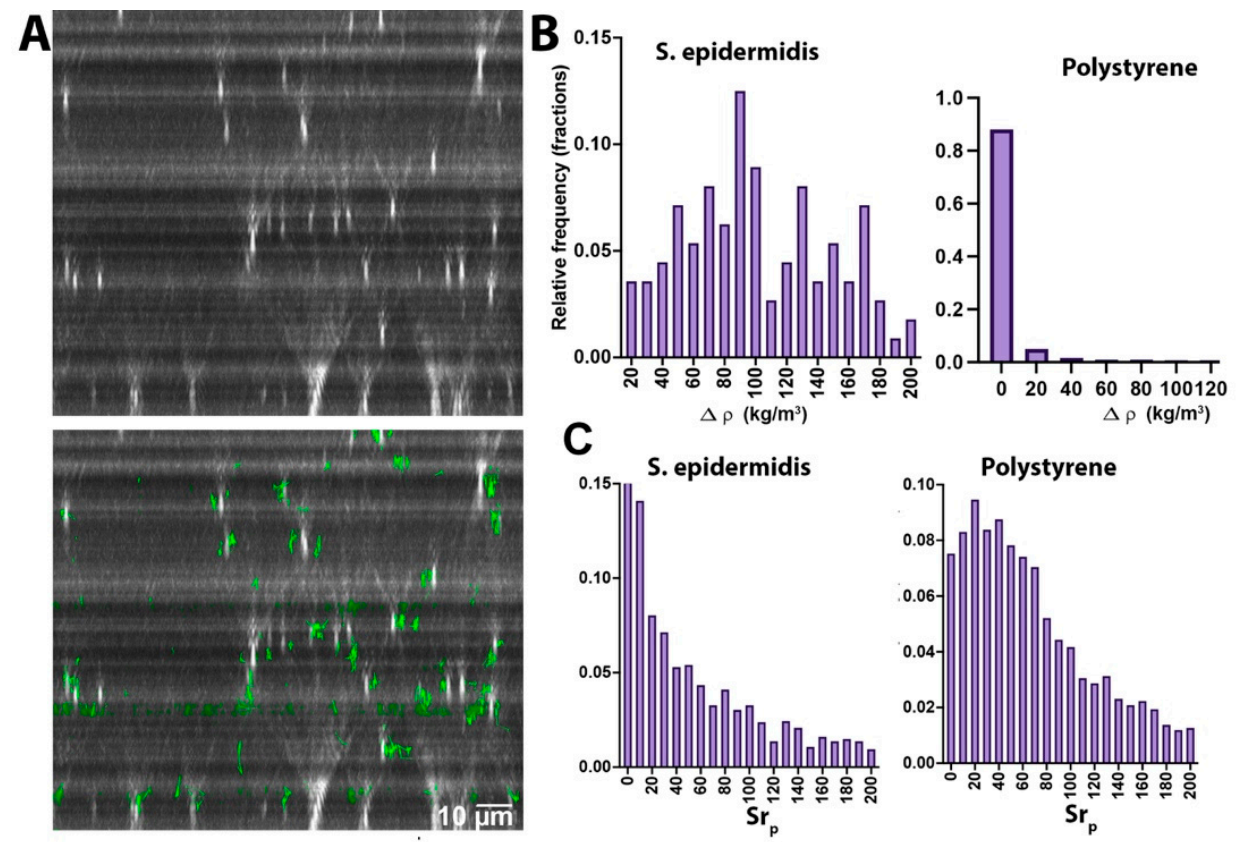

Figure 3. Neutrally buoyant particles. (A) S. epidermidis visualized in the XZ plane (top) and with tracks overlaid (bottom). (B) Calculated density differences vs. water based upon z velocities calculated for S. epidermidis and polystyrene, plotted with the same bin widths for easy comparison. (C) Strouhal number distributions for S. epidermidis and polystyrene.

For alumina, the particles sank or rose in a heterogeneous fashion, so $\mathrm{x} v \mathrm{vs} . \mathrm{z}$ motion of individual particles was examined at first rather than taking a mean value. Tracks could be matched in the $X Y$ and $X Z$ planes in order to match radii calculated from $X Y$ diffusivities with $z$ velocities calculated in $X Z$ (Figure $4 A, B$ ). Matching the radii and speeds gave a reasonable relationship of $\mathrm{z}$ velocity to radius relative to what was predicted from Equation (4) (Figure 4C). However, the relationship was fairly poor, indicating the stochastic nature of the processes being studied. In order to obtain a better relationship, longer trajectories of single particles would need to be obtained. We thus abandoned this approach and looked at mean values for all of the particles, where averaging over many trajectories substitutes for a single trajectory taken over a long time [53]. 


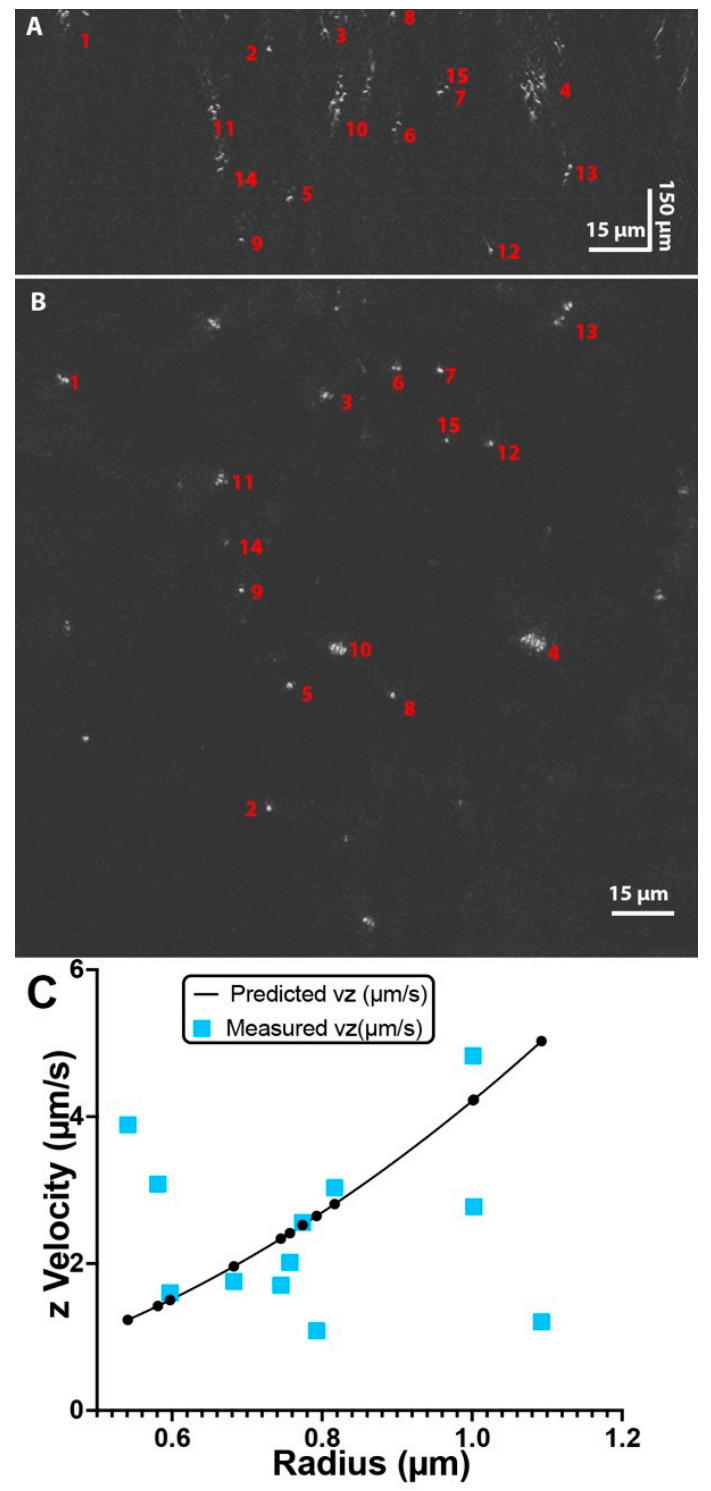

Figure 4. Matching particles in $X Y$ and $X Z$. (A) A single time frame of alumina particles in $X Z$. (B) The same time point in $X Y$, showing matched particles according to the $X$ coordinate. (C) Relationship of measured $\mathrm{z}$ velocities vs. radius (squares) to predicted $\mathrm{z}$ velocities (circles).

For alumina, the vertical XZT tracks shown in Figure 5A (also see Supplementary Video S6) indicate that sinking dominated in this sample. Particles could be tracked by traditional velocity-based tracking algorithms such as TrackMate. Alumina sank at a rate of $2.4 \pm 0.7 \mu \mathrm{m} / \mathrm{s}(\mathrm{N}=15)$, in excellent agreement with the predicted rate $(2.36 \mu \mathrm{m} / \mathrm{s}$ for a radius of $0.75 \mu \mathrm{m}$, Figure 1). Velocity distributions and Strouhal numbers are given in Figure 5B. 

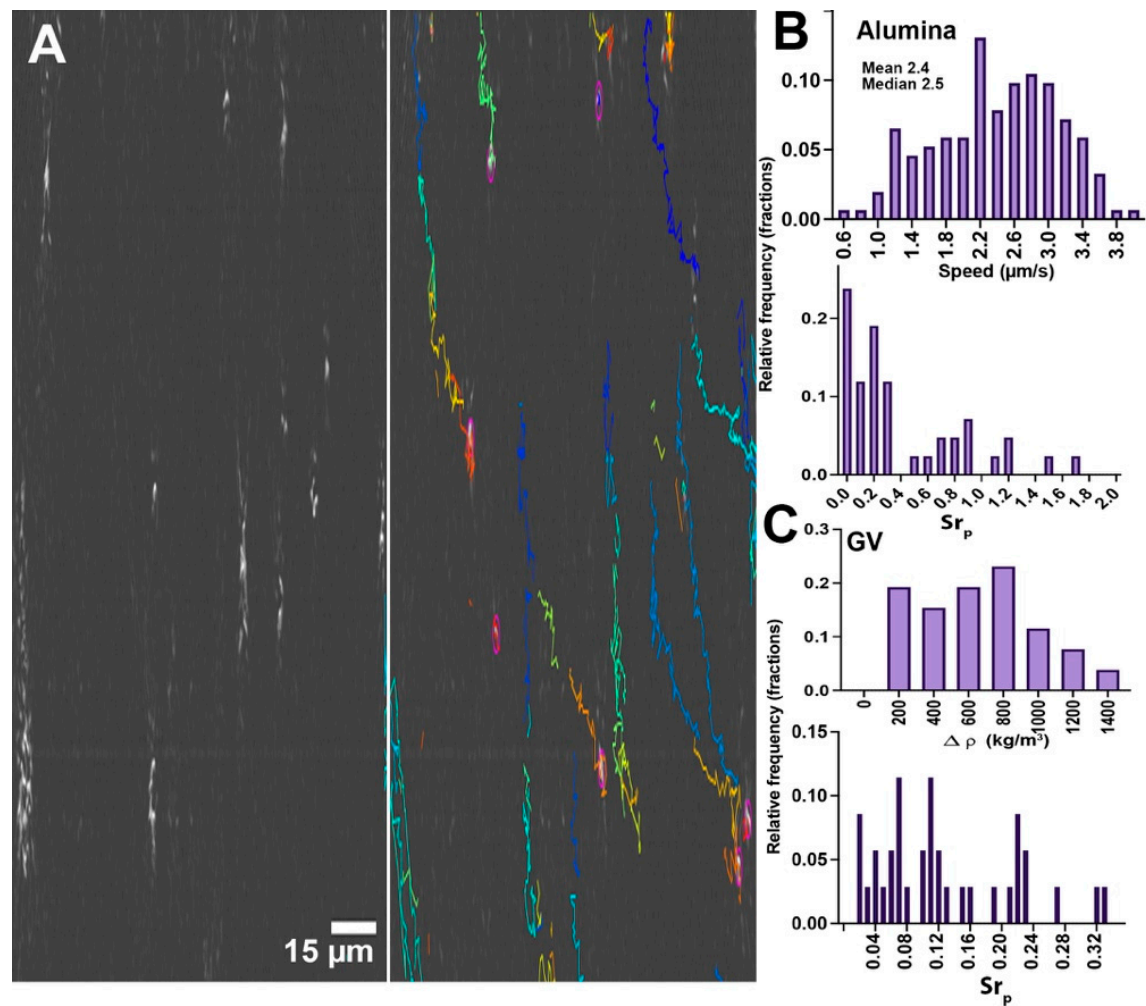

Figure 5. Particles with positive and negative buoyancy. (A) Alumina, showing the particles' appearance in the $\mathrm{XZ}$ plane and the tracks over $78 \mathrm{~s}$ of time. (B) Speed distribution of alumina particles and calculated Strouhal numbers for particles matched in XY and YZ. (C) Calculated density difference vs. water for the gas vesicles that showed the highest buoyancy (single peak in the $\mathrm{z}$ velocity distribution), and the Strouhal numbers for this subset of particles.

The gas vesicles also showed significant $\mathrm{z}$ motion, but floating rather than sinking (not shown) (see Supplementary Video S7). As expected, the velocities of the gas vesicles were multimodal. The most rapid subset had a mean rising velocity of $1.9 \mu \mathrm{m} / \mathrm{s}$, with a mean radius as measured by diffusivity of $1.0 \pm 0.2 \mu \mathrm{m}$ (median $0.9 \mu \mathrm{m}$ ), in good agreement with the value predicted by the Stokes equation of $1.9 \mu \mathrm{m} / \mathrm{s}$ for $\mathrm{r}=1.0 \mu \mathrm{m}$. The mean $\pm 95 \%$ CI estimated density difference was $670 \pm 130 \mathrm{~kg} / \mathrm{m}^{3}$. Density values and the calculated Strouhal numbers are given in Figure 5C.

\section{Discussion}

These results illustrate how the instantaneous and volumetric imaging capabilities of DHM allow it to discriminate between non-living and living particles of comparable sizes even in the absence of motility. By analyzing the three-dimensional passive dynamics of beads and non-motile bacteria, the radius and density of the materials may be calculated. Our diffusivities found for S. epidermidis are consistent with the Einstein model as well as reported values for other bacteria; for example, non-motile, nonflagellated E. coli at room temperature has been reported to have $\mathrm{D}_{X}=0.188 \mu \mathrm{m}^{2} / \mathrm{s}, \mathrm{D}_{\mathrm{Y}}=0.154 \mu \mathrm{m}^{2} / \mathrm{s}$ [54]. Most bacteria do have some degree of negative buoyancy as well, and we found that $30 \mathrm{~s}$ of recording was sufficient to distinguish $S$. epidermidis from polystyrene, which is almost perfectly neutrally buoyant.

Considering different gravities is important when thinking about space missions. Figure 6 shows $\log \left(S r_{p}\right)$ as a function of particle size and density for four different gravity environments of interest to the search for extant life: Earth, Europa, Enceladus, and Mars. These span roughly two orders of magnitude of gravity, but careful examination shows common features that can be used to aid in classifying particles. For terrestrial species and minerals, there is a gap between $\sim 1.3$ and $1.5 \mathrm{~g} / \mathrm{cm}^{3}$ density that helps distinguish cells 
or vesicles from minerals, so that even a $\sim 10 \%$ uncertainty in density will leave a clear separation. Terrestrial cells in aquatic environments have densities consistently less than $1.3 \mathrm{~g} / \mathrm{cm}^{3}$ (with most less than $1.2 \mathrm{~g} / \mathrm{cm}^{3}$ ) and very few minerals have densities as low as $1.5 \mathrm{~g} / \mathrm{cm}^{3}$. This is particularly useful if the size of the object can also be determined as above, as $S r_{p}$ for cell-like objects is $3 \times$ to $5 \times S r_{p}$ for the lightest minerals.

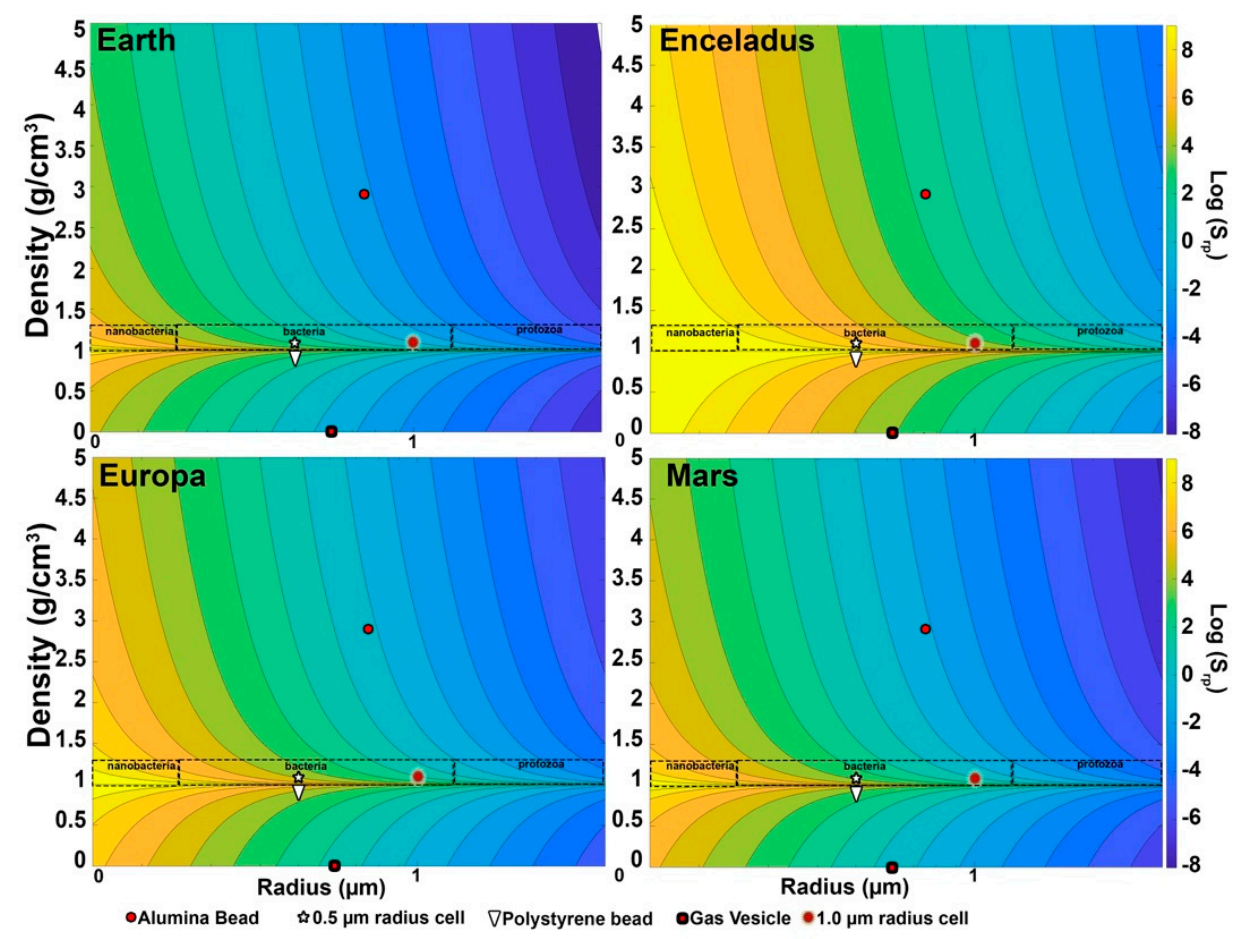

Figure 6. Strouhal numbers of our test samples under the different gravitational environments of selected planetary bodies.

On each body, the motion of particles with a radius larger than $\sim 1 \mu \mathrm{m}$ is gravity dominated and their density can be estimated from Stokes' Law (Equation (3)). Though Stokes' Law results are affected by geometry and surface properties of particles, objects in this size range are also resolvable by the microscopes described earlier and their size and shape can be directly measured and included in the classification process. At lower gravities and smaller sizes in this range, particles with densities in the cellular range are governed by both Brownian motion and gravity, and this type of mixed behavior is an indication for large particles that they are likely to be cell-like, as described below.

Below $\sim 1 \mu \mathrm{m}$ and down to 0.4 to $0.7 \mu \mathrm{m}$, depending on the gravity environment, particles generally fall into the Brownian-dominated or the mixed region. Within the mixed region, measurement of the diffusion constant can be used to determine particle size accurately, even below the optical resolution of the microscope. Sufficiently long observations can be used to measure the velocity well enough to obtain the difference in density from the surrounding fluid. On Earth, only $30 \mathrm{~s}$ of observation were required to distinguish bacteria from styrene beads by their buoyancy, a density difference of $\sim 0.05 \mathrm{~g} / \mathrm{cm}^{3}$. If we only require resolution of $\sim 0.1 \mathrm{~g} / \mathrm{cm}^{3}$, the time necessary is about $15 \mathrm{~s}$. Stokes' Law is linear in $g$, so on Europa or Mars the observation time necessary to distinguish minerals from cell-like objects would only be a few minutes. On Enceladus, with only $~ 1 \%$ of Earth's gravity, this would require on the order of $1500 \mathrm{~s}$, which might also impose requirements on the stability of the lander system during that time. Additional analyses, including index of refraction measurements from the DHM and fluorescence imaging, could be used to classify these objects. 


\section{Conclusions}

We have shown that the relative effects of Brownian motion and gravity can be measured with existing instruments to discriminate densities of objects of sizes and in gravitational environments that are of interest for life detection. While this approach does not directly determine if something is alive or not, it can provide strong support for whether an object is cell-like or mineral-like based on its density, with sensitivity to distinguish bacteria from neutrally buoyant polymers. When combined with other data that can be obtained simultaneously in a microscope (size, structure, refractive index, autofluorescence, stained fluorescence) it can strengthen the classification of whether a particular object is likely to be a live cell or inorganic mineral grain. This analysis adds to the toolbox for DHM analyses of samples containing bacteria and microminerals. Previous studies have indicated that DHM is an excellent technique for detection and classification of motile organisms, but that when microorganisms are non-motile and near the resolution limit, there is insufficient phase contrast or morphological information to confidently distinguish prokaryotes from microminerals. These new techniques may help to classify objects at the resolution limit as potentially biological or abiological. Future work will apply these methods to field samples containing unfiltered water samples and to other strains and life-cycle stages of bacteria, including those under heat or cold stress and toxin exposure.

Supplementary Materials: The following are available online at https:/ / www.mdpi.com/article/10 $.3390 /$ life11080793/s1, Video S1: alumina bead phase reconstruction in XY over 60 s; Video S2: S. epidermidis amplitude reconstruction in $X Y$ over $30 \mathrm{~s}$; Video S3: gas vesicle phase reconstruction in XY over 60 s; Video S4: S. epidermidis XZ plane over 30 s with identified tracks; Video S5: Polystyrene XZ plane over $30 \mathrm{~s}$; Video S6: alumina beads over $77 \mathrm{~s}$ in XZ; the Z scale is 10 times the X scale; Video S7: gas vesicles in in $X Z$ over $60 \mathrm{~s}$.

Author Contributions: Conceptualization, C.L. and J.N.; methodology, J.N.; software, all; validation, J.N.; formal analysis, D.R., C.L. and J.N.; resources, J.N.; data curation, C.L.; writing-original draft preparation, C.L.; writing-review and editing, J.N.; visualization, all; supervision, J.N.; project administration, J.N. and C.L.; funding acquisition, J.N. and C.L. All authors have read and agreed to the published version of the manuscript.

Funding: The work described in this paper was performed in part at the Jet Propulsion Laboratory, California Institute of Technology under contract with the National Aeronautics and Space Administration and at PSU under a contract from the Jet Propulsion Laboratory, California Institute of Technology and from NSF MRI grant \# 1828793.

Institutional Review Board Statement: Not applicable.

Informed Consent Statement: Not applicable.

Data Availability Statement: The raw holograms for the datasets used here are deposited in a public depository at Data Dryad, https:/ / doi.org/10.5061/dryad.n02v6wwxj (accessed on 5 August 2021). Other data are available from the authors upon request.

Acknowledgments: We thank Manuel Bedrossian for the gas vesicle and alumina recordings and Louis Sumrall for the polystyrene and S. epidermidis recordings.

Conflicts of Interest: The authors declare no conflict of interest. The funders had no role in the design of the study; in the collection, analyses, or interpretation of data; in the writing of the manuscript, or in the decision to publish the results.

\section{References}

1. Chyba, C.F.; Phillips, C.B. Europa as an Abode of Life. Orig. Life Evol. Biosph. 2002, 32, 47-68. [CrossRef] [PubMed]

2. Pappalardo, R.T.; Vance, S.; Bagenal, F.; Bills, B.G.; Blaney, D.L.; Blankenship, D.D.; Brinckerhoff, W.B.; Connerney, J.E.; Hand, K.P.; Hoehler, T.M.; et al. Science potential from a Europa lander. Astrobiology 2013, 13, 740-773. [CrossRef] [PubMed]

3. Prieto-Ballesteros, O.; Vorobyova, E.; Parro, V.; Manfredi, J.A.R.; Gomez, F. Strategies for detection of putative life on Europa. Adv. Space Res. 2011, 48, 678-688. [CrossRef]

4. McKay, C.P.; Porco, C.C.; Altheide, T.; Davis, W.L.; Kral, T. A The Possible Origin and Persistence of Life on Enceladus and Detection of Biomarkers in the Plume. Astrobiology 2008, 8, 909-919. [CrossRef] [PubMed] 
5. Tsou, P.; Brownlee, D.E.; McKay, C.P.; Anbar, A.D.; Yano, H.; Altwegg, K.; Beegle, L.W.; Dissly, R.; Strange, N.J.; Kanik, I. LIFE: Life Investigation For Enceladus A Sample Return Mission Concept in Search for Evidence of Life. Astrobiology 2012, 12, 730-742. [CrossRef]

6. Porco, C.C.; Dones, L.; Mitchell, C. Could It Be Snowing Microbes on Enceladus? Assessing Conditions in Its Plume and Implications for Future Missions. Astrobiology 2017, 17, 876-901. [CrossRef]

7. Hand, K.P. Report of the Europa Lander Science Definition Team. NASA. Available online: https://europa.nasa.gov/resources/ 58/europa-lander-study-2016-report/ (accessed on 10 August 2017).

8. $\quad$ Luef, B.; Frischkorn, K.R.; Wrighton, K.C.; Holman, H.Y.; Birarda, G.; Thomas, B.C.; Singh, A.; Williams, K.H.; Siegerist, C.E.; Tringe, S.G.; et al. Diverse uncultivated ultra-small bacterial cells in groundwater. Nat. Commun. 2015, 6, 6372. [CrossRef]

9. Nadeau, J.L.; Perreault, N.N.; Niederberger, T.D.; Whyte, L.G.; Sun, H.J.; Leon, R. Fluorescence Microscopy as a Tool for In Situ Life Detection. Astrobiology 2008, 8, 859-875. [CrossRef]

10. Nadeau, J.; Lindensmith, C.; Deming, J.W.; Fernandez, V.I.; Stocker, R. Microbial Morphology and Motility as Biosignatures for Outer Planet Missions. Astrobiology 2016, 16, 755-774. [CrossRef]

11. Seo, E.Y.; Ahn, T.S.; Zo, Y.G. Agreement, Precision, and Accuracy of Epifluorescence Microscopy Methods for Enumeration of Total Bacterial Numbers. Appl. Environ. Microbiol. 2010, 76, 1981-1991. [CrossRef]

12. Mitchell, J.G.; Kogure, K. Bacterial motility: Links to the environment and a driving force for microbial physics. FEMS Microbiol. Ecol. 2006, 55, 3-16. [CrossRef]

13. Son, K.; Brumley, D.R.; Stocker, R. Live from under the lens: Exploring microbial motility with dynamic imaging and microfluidics. Nat. Rev. Microbiol. 2015, 13, 761-775. [CrossRef] [PubMed]

14. Mitchell, J.G. The influence of cell size on marine bacterial motility and energetics. Microb. Ecol. 1991, 22, 227-238. [CrossRef]

15. Cayley, S.; Lewis, B.A.; Guttman, H.J.; Record, M.T., Jr. Characterization of the cytoplasm of Escherichia coli K-12 as a function of external osmolarity. Implications for protein-DNA interactions in vivo. J. Mol. Biol. 1991, 222, 281-300. [CrossRef]

16. Ayres, S.L. Cell Density (Mass per Unit Volume) of Diatom Cells and Chains in Relation to Their Size, Growth, and Nutritional Condition; University of Maine: Orono, ME, USA, 2017.

17. Vrieling, E.G.; Poort, L.; Beelen, T.P.M.; Gieskes, W.W.C. Growth and silica content of the diatoms Thalassiosira weissflogii and Navicula salinarum at different salinities and enrichments with aluminium. Eur. J. Phycol. 1999, 34, 307-316. [CrossRef]

18. Oliver, R.L.; Walsby, A.E. Buoyancy and suspension of planktonic cyanobacteria. Methods Enzymol. 1988, 167, 521-527.

19. Farhadi, A.; Ho, G.; Kunth, M.; Ling, B.; Lakshmanan, A.; Lu, G.; Bourdeau, R.W.; Schroder, L.; Shapiro, M.G. Recombinantly Expressed Gas Vesicles as Nanoscale Contrast Agents for Ultrasound and Hyperpolarized MRI. AIChE J. 2018, 64, 2927-2933. [CrossRef] [PubMed]

20. Farhadi, A.; Bedrossian, M.; Lee, J.; Ho, G.H.; Shapiro, M.G.; Nadeau, J.L. Genetically Encoded Phase Contrast Agents for Digital Holographic Microscopy. Nano Lett. 2020, 20, 8127-8134. [CrossRef]

21. Walsby, A.E.; Armstrong, R.E. Average thickness of the gas vesicle wall in Anabaena flos-aquae. J. Mol. Biol. 1979, 129, 279-285. [CrossRef]

22. Maggi, F. The settling velocity of mineral, biomineral, and biological particles and aggregates in water. J. Geophysical. Res.-Oceans 2013, 118, 2118-2132. [CrossRef]

23. Dunderdale, G.; Ebbens, S.; Fairclough, P.; Howse, J. Importance of particle tracking and calculating the mean-squared displacement in distinguishing nanopropulsion from other processes. Langmuir 2012, 28, 10997-11006. [CrossRef]

24. Wallace, J.K.; Rider, S.; Serabyn, E.; Kuhn, J.; Liewer, K.; Deming, J.; Showalter, G.; Lindensmith, C.; Nadeau, J. Robust, compact implementation of an off-axis digital holographic microscope. Opt. Express 2015, 23, 17367-17378. [CrossRef] [PubMed]

25. Lindensmith, C.A.; Rider, S.; Bedrossian, M.; Wallace, J.K.; Serabyn, E.; Showalter, G.M.; Deming, J.W.; Nadeau, J.L. A Submersible, Off-Axis Holographic Microscope for Detection of Microbial Motility and Morphology in Aqueous and Icy Environments. PLoS ONE 2016, 11, e0147700. [CrossRef]

26. Kuhn, J.; Niraula, B.; Liewer, K.; Kent, W.J.; Serabyn, E.; Graff, E.; Lindensmith, C.; Nadeau, J.L. A Mach-Zender digital holographic microscope with sub-micrometer resolution for imaging and tracking of marine micro-organisms. Rev. Sci. Instrum. 2014, 85, 123113. [CrossRef] [PubMed]

27. Gurkan, U.A.; Moon, S.; Geckil, H.; Xu, F.; Wang, S.Q.; Lu, T.J.; Demirci, U. Miniaturized lensless imaging systems for cell and microorganism visualization in point-of-care testing. Biotechnol. J. 2011, 6, 138-149. [CrossRef]

28. El Mallahi, A.; Minetti, C.; Dubois, F. Automated three-dimensional detection and classification of living organisms using digital holographic microscopy with partial spatial coherent source: Application to the monitoring of drinking water resources. Appl. Optics 2013, 52, A68-A80. [CrossRef]

29. Cross, J.; Nimmo-Smith, W.A.M.; Hosegood, P.J.; Torres, R. The role of advection in the distribution of plankton populations at a moored 1-D coastal observatory. Progress Oceanogr. 2015, 137, 342-359. [CrossRef]

30. Guo, B.Y.; Nyman, L.; Nayak, A.R.; Milmore, D.; McFarland, M.; Twardowski, M.S.; Sullivan, J.M.; Yu, J.; Hong, J.R. Automated plankton classification from holographic imagery with deep convolutional neural networks. Limnol. Oceanogr. -Methods 2021, 19, 21-36. [CrossRef]

31. Monaldi, A.C.; Romero, G.G.; Alanis, E.E.; Cabrera, C.M. Digital holographic microscopy for microalgae biovolume assessment. Optics Commun. 2015, 336, 255-261. [CrossRef] 
32. Orzo, L.R.; Varecza, Z.A.; Kiss, M.Z.; Zarandy, A. Application of Digital Holographic Microscopy for Automatic Monitoring of Freely Floating Microorganisms. Ercim News 2017, 108, 18-19.

33. Romero, G.G.; Monaldi, A.C.; Alanis, E.E. Digital holographic microscopy for detection of Trypanosoma cruzi parasites in fresh blood mounts. Opt. Commun. 2012, 285, 1613-1618. [CrossRef]

34. Sheng, J.; Malkiel, E.; Katz, J.; Adolf, J.; Belas, R.; Place, A.R. Digital holographic microscopy reveals prey-induced changes in swimming behavior of predatory dinoflagellates. Proc. Natl. Acad. Sci. USA 2007, 104, 17512-17517. [CrossRef]

35. Bianchi, S.; Saglimbeni, F.; Di Leonardo, R. Holographic Imaging Reveals the Mechanism of Wall Entrapment in Swimming Bacteria. Phys. Rev. X 2017, 7, 011010. [CrossRef]

36. DaneshPanah, M.; Javidi, B. Tracking biological microorganisms in sequence of 3D holographic microscopy images. Opt. Express 2007, 15, 10761-10766. [CrossRef]

37. Frentz, Z.; Kuehn, S.; Hekstra, D.; Leibler, S. Microbial population dynamics by digital in-line holographic microscopy. Rev. Sci. Instrum. 2010, 81, 084301. [CrossRef]

38. Lee, S.J.; Go, T.; Byeon, H. Three-dimensional swimming motility of microorganism in the near-wall region. Exp. Fluids 2016, 57, 26. [CrossRef]

39. Lee, S.J.; Seo, K.W.; Choi, Y.S.; Sohn, M.H. Three-dimensional motion measurements of free-swimming microorganisms using digital holographic microscopy. Meas. Sci. Technol. 2011, 22, 064004. [CrossRef]

40. Bedrossian, M.; Barr, C.; Lindensmith, C.A.; Nealson, K.; Nadeau, J.L. Quantifying Microorganisms at Low Concentrations Using Digital Holographic Microscopy (DHM). J. Vis. Exp. 2017, 129, 56343. [CrossRef]

41. Bedrossian, M.; Lindensmith, C.; Nadeau, J.L. Digital Holographic Microscopy, a Method for Detection of Microorganisms in Plume Samples from Enceladus and Other Icy Worlds. Astrobiology 2017, 17, 913-925. [CrossRef]

42. Strouhal, V. Uber eine besondere Art der Tonerregung. Ann. Phys. 1878, 5, 216-251. [CrossRef]

43. Guasto, J.S.; Rusconi, R.; Stocker, R. Fluid Mechanics of Planktonic Microorganisms. Annu. Rev. Fluid Mech. 2012, 44, 373-400. [CrossRef]

44. Fregoso, S.F.; Lima, F.; Wallace, J.K.; Bedrossian, M.; McKeithen, D.; Kettenbeil, C.; Loya, F.; Lindensmith, C. DHMx (Digital Holographic Microscope Experience) Software Tool. In Digital Holography and Three-Dimensional Imaging; Optical Society of America: Washington, DC, USA, 2020.

45. Mann, C.J.; Kim, M.K. Quantitative phase-contrast microscopy by angular spectrum digital holography. In Three-Dimensional and Multidimensional Microscopy: Image Acquisition and Processing XIII; SPIE: Bellingham, WA, USA, 2006; Volume 6090.

46. Cohoe, D.; Hanczarek, I.; Wallace, J.K.; Nadeau, J. Multiwavelength digital holographic imaging and phase unwrapping of protozoa in amplitude and phase using custom Fiji plug-ins. Front. Phys. 2019, 7, 94. [CrossRef]

47. Colomb, T.; Kuhn, J.; Charriere, F.; Depeursinge, C.; Marquet, P.; Aspert, N. Total aberrations compensation in digital holographic microscopy with a reference conjugated hologram. Opt. Express 2006, 14, 4300-4306. [CrossRef] [PubMed]

48. Schindelin, J.; Arganda-Carreras, I.; Frise, E.; Kaynig, V.; Longair, M.; Pietzsch, T.; Preibisch, S.; Rueden, C.; Saalfeld, S.; Schmid, B.; et al. Fiji: An open-source platform for biological-image analysis. Nat. Methods 2012, 9, 676-682. [CrossRef] [PubMed]

49. Gibson, T.; Bedrossian, M.; Serabyn, E.; Lindensmith, C.; Nadeau, J.L. Using the Gouy phase anomaly to localize and track bacteria in digital holographic microscopy 4D images. J. Opt. Soc. Am. Opt. Image Sci. Vis. 2021, 38, A11-A18. [CrossRef] [PubMed]

50. Bedrossian, M.; Wallace, J.K.; Serabyn, E.; Nadeau, J. Enhancing final image contrast in off-axis digital holography using residual fringes. Opt. Express 2020, 28, 16764-16771. [CrossRef]

51. Wagner, T.; Lipinski, H.G.; Wiemann, M. Dark field nanoparticle tracking analysis for size characterization of plasmonic and non-plasmonic particles. J. Nanopart. Res. 2014, 16, 2419. [CrossRef]

52. Walker, J.G. Improved nano-particle tracking analysis. Meas. Sci. Technol. 2012, 23, 065605. [CrossRef]

53. Sposini, V.; Metzler, R.; Oshanin, G. Single-trajectory spectral analysis of scaled Brownian motion. New J. Phys. 2019, 21, 073043. [CrossRef]

54. Tavaddod, S.; Charsooghi, M.A.; Abdi, F.; Khalesifard, H.R.; Golestanian, R. Probing passive diffusion of flagellated and deflagellated Escherichia coli. Eur Phys. J. E Soft Matter 2011, 34, 16. [CrossRef] 